\title{
EFFECT OF ORGANOPHILIZATION AND INTERLAMELLAR SILYLATION OF MONTMORILLONITE ON COMPATIBLIZATION OF POLYMER COMPOSITES
}

\author{
Mamdouh Abdel Rahim ${ }^{1}$, Mohamed Ismail², Ahmed Kandil ${ }^{3}$ \\ 1 Department of Chemistry, Faculty of Science, University of Cairo, Giza, 12613, Egypt \\ 2 Department of Chemical Engineering, Military Technical Faculty, Cairo, 11787, Egypt \\ 3 Department of Chemistry, Science \&Technology Center of Excellence, Cairo, 11825, Egypt, e-mail: \\ mahrousse_81@yahoo.com
}

Received: 2016.07.31

Accepted: 2016.09 .17

Published: 2016.12.01

\begin{abstract}
Sodium montmorillonite (Na-Mt) was modified by cetyltriemethylammoniumbromide (CTAB) through cation exchange technique followed by grafting with 3-aminopropyltriethoxysilane (APT). The effects of organophillic surface treatments of montmorillonite on compatibilization of natural rubber (NR) /acrylonitrile butadiene rubber (NBR) blends was investigated. Physico-mechanical properties of rubber nanocomposites compatibilized with organomodified montmorillonite revealed strong nanocomposite with high tensile properties, impact strength and good resistance to flex fatigue, abrasion and compression set. Dynamic mechanical thermal analysis (DMTA) revealed a marked increase in storage modulus $\left(E^{\prime}\right)$ and lesser damping characteristics of organically modified clay mineral polymer nanocomposites (CPN) due to intercalation of organophilic montmorillonite by rubber matrix. The morphology of the blends became homogeneous and smoother with the presence of exofoliated/intercalated organically modified montmorillonite. Organomodified layered silicate sheets of montmorillonite greatly enhanced barrier properties by creating tortuous path that retarded the progress of solvent molecules through rubber matrix.
\end{abstract}

Keywords: nanocomposites, montmorillonite, organophilization, polymer composites, compatibilization.

\section{INTRODUCTION}

Blending of different rubber polymers is an effective and economic approach to enhance the performance characteristics of rubber products $[1,2]$. The efficiency of interfacial cross-linking in rubber blends is governed by various factors including the nature of blend compositions, processing condition and phase morphology of rubber blends [3]. It is very often that components are grossly immiscible as well as technologically incompatible [4]. The lack of miscibility and technological compatibility of the component rubber polymers severely restricts the application of rubber blends. It has been reported the use of nanofillers of inorganic nature for the purpose of compatiblization and reinforcement of incompatible pairs of polymer [5]. Montmorillonite is one of the commercial layered silicates and has been widely used as reinforcing filler in the preparation of nanocomposites [6]. However, the hydrophilic nature of montmorillonite limits its compatibility with hydrophobic polymers. Thus, chemical modification has been developed to make montmorillonite compatible with polymers. The surface of montmorillonite is commonly modified with a cation exchange technique to expand the basal spacing and make the layered silicate compatible with most hydrophobic polymer [7]. Because of the weak interactions between the nano- 
layers, the cations can be easily exchanged with alkyl ammonium cations, or phophonium salts thus making the layered silicate compatible with the rubber matrix $[8,9]$. Also organochlorosilanes are used for the modification of montmoriollinite silica surfaces, by covalent grafting on interfaces [10]. In this study, the effect of intercalation of APT and CTAB into Na-Mt to improve the miscibility of the NR/NBR blends was investigated. The compatibility between the NR and NBR was studied by examining the morphology, mechanical and dynamic mechanical thermal properties as well as barrier properties of blends nanocomposites.

\section{EXPERIMENTAL}

\section{Materials}

Elastomers used throughout this work are:

- Natural rubber (NR) (ribbed smoked sheets), was supplied from Vitmas, India (specific gravity, 0.915).

- Nitrile butadiene rubber (NBR) containing $34 \%$ acrylonitrile content was supplied from Polysar LTD, Canada (specific gravity, 0.98).

All other rubber ingredients used were of laboratory reagent grade, supplied by Bayer, Germany. High purity solvents analytical grade benzene, butyl acetate and ethanol were obtained from EL - NASR Pharmaceutical Chemicals Co., A.R.E. Montmorillonite (Mt), in the form of 300mesh powder in its sodium form (Na-Mt) with cation exchange capacity $119 \mathrm{meq} / 100 \mathrm{~g}$ was purchased from Sigma Aldrich (USA); specification of montmorillonite is given below (Table 1). Cetyltrimethylammoniumbromide $\left(\mathrm{C}_{19} \mathrm{H}_{42} \mathrm{BrN}\right)$ at $98 \%$ purity and 3-aminopropyltriethoxysilane $\left(\mathrm{C}_{9} \mathrm{H}_{23} \mathrm{NO}_{3} \mathrm{Si}\right)$ at $96 \%$ purity were purchased from Sigma Aldrich (USA) and used as organic modifiers of montmorillonite.

\section{Organophilization of montmorillonite}

$10 \mathrm{~g}$ of Na-Mt was dispersed in 1 litre of distilled water and stirred for 30 minutes. An aqueous solution of 12 millimoles of cetyltrimethylammoniumbromide (CTAB) was added to the Na-Mt dispersion with continuous stirring for 3 hours at $80^{\circ} \mathrm{C}$. The solution was left idle overnight. The product was then filtered, washed several times with hot distilled water until no bromide was detected with $0.1 \mathrm{M} \mathrm{AgNO}_{3}$ solution and vacuum dried. The cation exchanged Na-Mt was ground using a mortar and pestle to produce (OMt). The silylation reaction was performed at a weight ratio of 1:1 of OMT/ APT. To perform the silylation reaction of OMt by 3-aminopropyltriethoxysilane (APT), solution of 3-aminopropyltriethoxysilane (APT) in $200 \mathrm{ml}$ ethanol was prepared. The previously prepared OMt was dispersed in APT solution (ultrasound for $30 \mathrm{~min}$ ) at room temperature. The dispersion was evaporated to dryness for 24 $\mathrm{h}$ at $50^{\circ} \mathrm{C}$ to produce (APT- OMt).

\section{Characterization of montmorillonite}

The three samples (Na-Mt, OMt and APT$\mathrm{OMt}$ ) were characterized with:

- Scanning electron microscope (SEM) which was employed to study the microstructure distribution of montmorillonite using Philips XL 30 scanning electron microscope operated at an accelerating voltage of $20 \mathrm{kV}$ and a magnification 1500 times the origin specimen size.

- Specific surface areas by $\mathrm{N}_{2}$ physisorption analysis. Nitrogen adsorption/desorption isotherms were measured at $77 \mathrm{~K}$, using a Quantachrome Autosorb-1 computer controlled apparatus. The nitrogen sorption data was used to compute the total specific surface area (SSABET), external specific surface area (SSAext) and the total pore volume (VMP) following the t-plot method [11]. The total pore volume (VMP) was calculated from the amount of nitrogen vapour adsorbed at a relative pressure close to unity. The sizes of the primary and agglomerated particles were calculated using the different specific surface areas determined by the BET method (SSABET) and by geometrical considerations (SSASph) [12]. The BJH method was applied for the adsorption and desorption isotherms to derivate the pore-size distribution [13].

- Infrared measurements were run with a JASCO instrument (FT/IR-6100 type A) with the following conditions: wave number range: 400-4000 cm $\mathrm{cm}^{-1}$; aperture setting: $3.5 \mathrm{~mm}$; scanner velocity: $2.2 \mathrm{kHz}$; background scan time: $32 \mathrm{sec}$; sample scan time: $32 \mathrm{sec}$; resolution $6 \mathrm{~cm}^{-1}$; beam spliter: $\mathrm{KBr}$; angle of incident radiation: $45^{\circ}$.

- X-ray diffraction (XRD) which was recorded on ARL X'TRA diffractometer, $\mathrm{Cu}-\mathrm{K} a$ radiation $(\lambda=0.154056 \mathrm{~nm})$, operating at $40 \mathrm{kV} / 300 \mathrm{~mA}$, data were collected within the range of scattering angles $(2 \theta)$ of 3 to $10^{\circ}$ at the rate of $2 \% \mathrm{~min}$. 
- Thermogravimetric analysis (TGA) with TGA Q500 thermobalance (TA instruments), samples were heated from room temperature to $900^{\circ} \mathrm{C}$ at a heating rate of $10^{\circ} \mathrm{C} / \mathrm{min}$ under nitrogen flow.

\section{Blend preparation}

NR/NBR blends (50:50 wt \%) were carried out in a laboratory-sized two-roll mill (Model XK160) of $470 \mathrm{~mm}$. diameter and $300 \mathrm{~mm}$. working distance, the speed of the slow roller was 24 r.p.m. with a gear ratio of $1: 1.4$. The rubber was mixed with ingredients according to ASTM D3184. The ingredients mixed with the blends are: stearic acid (1 phr), $\mathrm{ZnO}(5 \mathrm{phr})$, Pentaerythritol tetrakis (3-(3,5-di-tert-butyl-4-hydroxyphenyl)propionate) (Irganox 1010) (1 phr), processing oil (3 $\mathrm{phr}), 2$ - mercapto benzo thiazole (MBT) $(0.7 \mathrm{phr})$, 2,2-dibenzothiazole disulfide (MBTS) (0.5 phr) and sulfur (2.5 phr). Different amounts of Na-MT, OMT and APT-OMt were then added [0, 1, 2, 3, 4 , and 5 parts per hundred rubbers (phr)]. Filler content (Na-Mt-1) means rubber nanocomposite filled with $1 \mathrm{phr} \mathrm{Na}-\mathrm{Mt}$; other filler contents were defined similarly. The samples were compression molded at $150^{\circ} \mathrm{C}$ with a cure time of $\mathrm{tC} 90$ obtained from an oscillating disc rheometer (Zwick 4308).

\section{CHARACTERIZATION OF BLEND NANOCOMPOSITES}

\section{Processability and cure characteristics}

Cure characteristics were studied using moving die rheometer (Zwick 4308, Germany) according to ASTM D2084. Samples (4g) of the respective compounds were tested at the vulcanization temperature $\left(150^{\circ} \mathrm{C}\right)$. Mooney viscosity (ML1 + 4@100 ${ }^{\circ} \mathrm{C}$ ) was determined using a mooney viscometer (MV 2000) according to the method described in ASTM D1646.

\section{Mechanical properties}

Tensile strength (Ts), elongation at break (Eb) and modulus (M) at 200\% elongation were measured using universal testing material (Zwick 1445) with cross-head speed of 5 $\mathrm{mm} / \mathrm{min}$., according to ASTM D 638-99. Izod impact strength (IS) of the notched specimens was carried out according ASTM D256 by (Ray Ran) universal pendulum impact machine.
Specimens with dimension of $63 \times 12.7 \times 3 \mathrm{~mm}^{3}$ were prepared and an angle of $60^{\circ}$ with 2.54 $\mathrm{mm}$ depth was cut by rotating saw using (Ray Ran) motorized notching cutter machine. The impact tests were carried out at room temperature and impact energy was reported in $\mathrm{KJ} / \mathrm{m}$. The hardness $(\mathrm{H})$ of the blends was measured according to ASTM D 2240 test method at room temperature using (Zwick 3105) digi test - Digital IRHD/Shore hardness tester. Abrasion loss (Ab \%) was determined using (Wallace Akron) tester according to ASTM D5963 test method as relative percentage of volume loss, abrasion resistance index (ARI \%) was determined by using the following equation:

$$
A R I \%=(\mathrm{S} / \mathrm{T}) \times 100
$$

where: $\mathrm{S}$ is the standard sample volume loss and $\mathrm{T}$ is the volume loss of the test sample.

Flex fatigue covers the determination of crack growth of vulcanized rubber when subjected to repeated bending strain or flexing according to ASTM D813 using (Wallace De Mattia) flexing machine. Compression set was measured using (Wallace) compression set machine. The standard test specimen is a cylindrical disk cut or molded with specific dimensions according to ASTM D395 after the rest period of $30 \mathrm{~min}$., the final thickness at the center of the specimens measured and the compression set is calculated as a percentage of the original thickness as expressed in the following equation:

$$
\mathrm{Cs} \%=\frac{t_{o}-t_{r}}{\mathrm{t}_{\mathrm{r}}} \times 100
$$

where: Cs is the compression set, $\mathrm{t}_{\mathrm{o}}$ is the original thickness and $t_{r}$ is the final thickness.

\section{Dynamic mechanical thermal analysis (DMTA)}

Dynamic mechanical thermal properties of the compounds were analyzed using a TA Instrument DMA 2980 mode. The samples were subjected to a sinusoidal displacement at a frequency of $1 \mathrm{~Hz}$ between the temperatures ranging from room temperature to $100^{\circ} \mathrm{C}$ at a heating rate of $3^{\circ} \mathrm{C} \mathrm{min}^{-1}$.

\section{MORPHOLOGY}

\section{Scanning electron microscope}

Philips XL 30 scanning electron microscope operated at an accelerating voltage of $20 \mathrm{kV}$ and 
spot magnification 1500x was employed to study the morphology of rubber blend nanocomposites. The filled samples were firstly immersed in liquid $\mathrm{N}_{2}$, and then broken. After that, the samples were mounted on an aluminum stub and sputter coated with a thin layer of gold to prevent electrical charging during the observation.

\section{Transmission electron microscope}

Dispersion morphology of montmorillonite incorporated in rubber matrix was observed in the high-resolution transmission electron microscope (TEM, JEOL 2100). For the HR-TEM observation, ultra-thin cross-sections of the specimens were carried out by using a Leica Ultra cut UCT ultramicrotome equipped with a diamond knife. The thicknesses of the HR-TEM specimens were approximately $80 \mathrm{~nm}$.

\section{Adsorption experiment}

Analytical grade solvents used in this experiment were benzene and butyl acetate. The rubber samples were cut circularly, the thickness of the membrane was measured at several points using a micrometer screw gauge and average value was taken. The samples were removed from the bottles at intervals and weighed. They were then replaced in the test bottles until equilibrium swelling was attained. The weightings were accurate up to $0.001 \mathrm{~g}$. The results of adsorption experiments were expressed as moles of solvent uptake by $100 \mathrm{~g}$ of crosslinked NR/NBR samples (Q, mol\%).

$\mathrm{Q}_{\mathrm{t}} \mathrm{mol} \%=\frac{\left(\frac{\text { Mass of solvent sorbed }}{\text { Molar mass of solvent }}\right)}{\text { Mass of polymer }} \times 100$

\section{RESULTS AND DISCUSSION}

\section{Characterization of montmorillonite}

SEM micrographs recorded for both modified and unmodified Na-Mt are shown in Figure 1. The micrographs distinguishes individual layer blocks of unmodified Na-Mt, physical van der walls bonding of face to face and face to edge takes place and thus a rigid structure is confirmed. In contrast, the presence of CTAB and APT surfactant on the surface and inside the interlayer spaces produces a more open structure that will
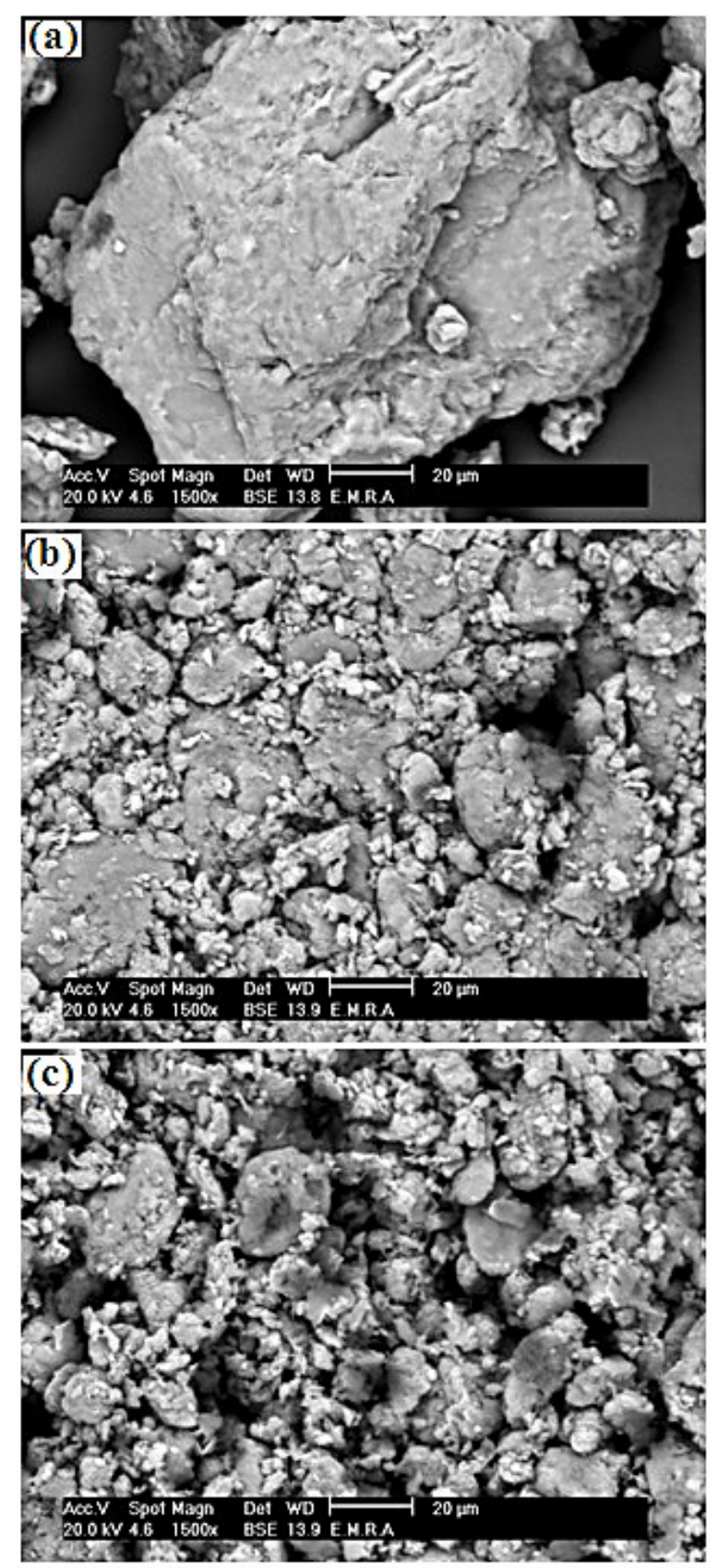

Fig. 1. SEM micrograph of: a) Na-Mt, b) OMt, c) APT-OMt

favor further exfoliation during polymeric nanocomposites fabrication.

Table 2 represents textural properties of modified and unmodified $\mathrm{Na}-\mathrm{Mt}$, as to be expected the SSABET and SSAext are larger with organomodified montmorillonite, this parameter is strongly related to pore volume (VMP), which tends to increase by organophilization of Mt and the capillary (pore) diameter (dp) tends to increase via organophilization. Based on the calculated agglomeration ratio (dagg/ dBET), which can give indications about the degree of agglomeration of 
Table 1. Specification of Na-Mt

\begin{tabular}{|c|c|}
\hline $\mathrm{SiO}_{2}$ & $46.3 \%$ \\
\hline $\mathrm{Al}_{2} \mathrm{O}_{3}$ & $17.3 \%$ \\
\hline $\mathrm{Na}_{2} \mathrm{O}$ & $1.5 \%$ \\
\hline $\mathrm{Ca}_{2} \mathrm{O}$ & $1.3 \%$ \\
\hline $\mathrm{Fe}_{2} \mathrm{O}_{3}$ & $14.2 \%$ \\
\hline $\mathrm{Moisture}$ & $9.0 \%$ \\
\hline $\mathrm{pH}$ & 8.5 \\
\hline
\end{tabular}

the different studied samples, we can conclude that Na-Mt particles, are highly agglomerated (ratio higher than 2), which can lead to undesired effects on the rubber performance. On the other hand, organomodified montmorillonite samples display low agglomeration (lower than 2), which in theory should lead to a better dispersion of the particles during the rubber mixing. Figure 2 represents adsorption isotherms obtained for unmodified and organically modified montmorillonite. The samples are of type IV isotherms according to the Brunauer-Deming-Deming-Teller (BDDT) classification. The presence of a hysteresis loop in the desorption isotherm of organomodified montmorillonite shows that the samples are mesoporoous. The peak intensity of unmodified montmorillonite are quite low in comparison to organomodified montmorillonite, and have bimodal curve, which indicates that $\mathrm{Na}-\mathrm{Mt}$ have low mesoporous character and non-uniform aggregation of secondary particles (microspheres) because of their better crystallization and lower pore volume.

Figure 3 shows the FTIR spectrum of unmodified and organically modified montmorillonite. The infrared spectrum of the unmodified montmorillonite presents two peaks, which corresponds to the Si-O stretching $\left(1057 \mathrm{~cm}^{-1}\right)$ and $-\mathrm{OH}$ groups $\left(3638 \mathrm{~cm}^{-1}\right)$. All the two organically modified montmorillonite present extra peaks in the FTIR spectrum. The occurrence of extra peaks at around 2936 and $2885 \mathrm{~cm}^{-1}$ for organically modified montmorillonite suggests the presence of grafted organic moieties onto the montmorillonite surface. Bands at 2936 and $2885 \mathrm{~cm}^{-1}$ are

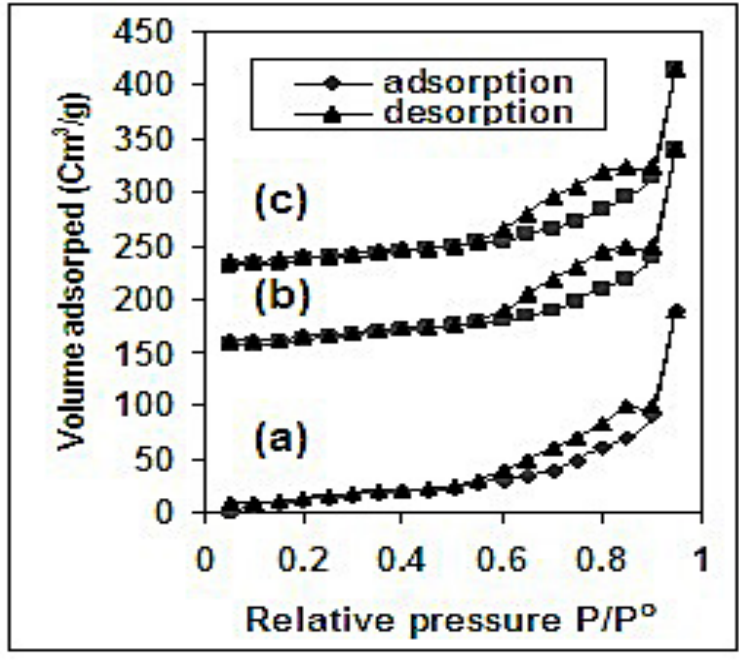

Fig. 2. $\mathrm{N}_{2}$ adsorption isotherms of: a) Na-Mt, b)OMt, c) APT-OMt (77K)

attributed to the $\mathrm{C}-\mathrm{H}$ asymmetric and symmetric stretching vibrations of the modifying groups, respectively. The band around $1470 \mathrm{~cm}^{-1}$ for the modified clays is assigned to the ammonium salt.

$\mathrm{X}$-ray diffraction of modified and unmodified $\mathrm{Na}-\mathrm{Mt}$ is shown in figure 4 . The results indicate that Na-Mt has a reflection at $2 \theta=6.9^{\circ}$ which is assigned to an interlayer spacing of $12.7 \mathrm{~A}^{\circ}$. In the case of organomodified montmorillonite, the organic cations penetrate into the interlayer space, replacing the sodium cation and reflection position shifts to a lower angle. The interlayer distance of organomodified montmorillonite gets increased to $17.11 \mathrm{~A}^{\circ}, 19.162 \mathrm{~A}^{\circ}$ for O-Mt and APT- OMt respectively.

Thermograms and derivative thermograms of unmodified and organomodified montmorillonite are shown in figure 5. Unmodified montmorillonite (Na-Mt) displays two weight loss peaks at $61^{\circ} \mathrm{C}$ and $94^{\circ} \mathrm{C}$ corresponding to the loss of hydrated water of the interlayer cations and three peaks at $588^{\circ} \mathrm{C}, 700^{\circ} \mathrm{C}$ and $813^{\circ} \mathrm{C}$ corresponding to the degradation of structural hydroxyls. Unmodified montmorillonite is stable in the temperature range of $227-500^{\circ} \mathrm{C}$, while organomodified montmorillonite displays degradation peaks correspond to the evaporation of physically adsorbed

Table 2. Textural parameters of unmodified and organomodified montmorillonite

\begin{tabular}{|l|c|c|c|c|c|}
\hline \multicolumn{1}{|c|}{ Sample } & $\begin{array}{c}\text { SSABET } \\
\left(\mathrm{m}^{2} / \mathrm{g}\right)\end{array}$ & $\begin{array}{c}\text { SSAext } \\
\left(\mathrm{m}^{2} / \mathrm{g}\right)\end{array}$ & $\begin{array}{c}\text { VMP } \\
\left(\mathrm{cm}^{3} / \mathrm{g}\right)\end{array}$ & $\begin{array}{c}\mathrm{dp}, \\
\mathrm{ad}(\mathrm{nm})\end{array}$ & $\left(\mathrm{d}_{\mathrm{agg}} / \mathrm{d}_{\mathrm{BET}}\right)$ \\
\hline Na-Mt & 62 & 52.3 & 0.12 & 1.23 & 2.5 \\
\hline OMt & 190 & 72.3 & 0.21 & 2.12 & 1.4 \\
\hline APT-OMt & 270 & 96.5 & 0.33 & 3.54 & 1.1 \\
\hline
\end{tabular}




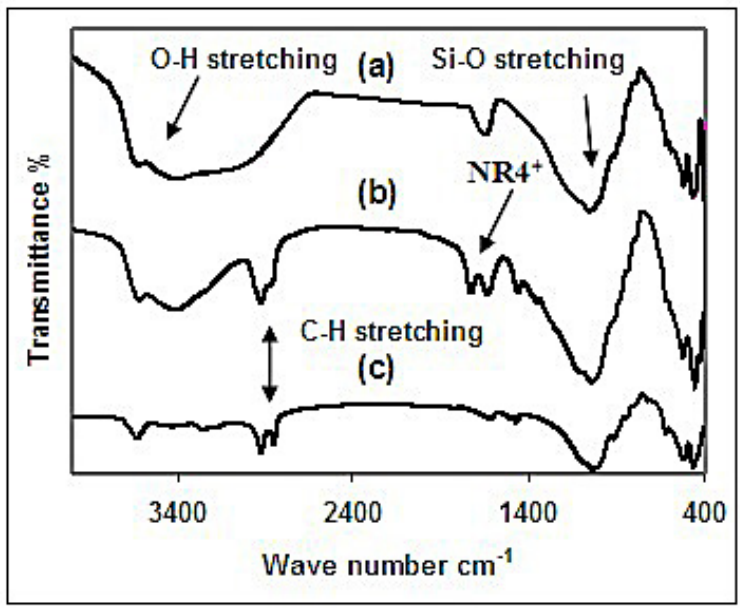

Fig. 3. FTIR Spectrum of: a) Mt, b) O-Mt, c) APT- OMt

and grafted organic moieties which displays maximum decomposition temperature $\left(\mathrm{T}_{\max }\right)$ at 317 ${ }^{\circ} \mathrm{C}$ for $\mathrm{O}-\mathrm{Mt}$ and shifted to higher degradation temperature at $360^{\circ} \mathrm{C}$ for APT- OMt.

\section{Rheological properties}

Rheological properties of NR/NBR blends filled with unmodified and organomodified montmorillonite are shown in Table 3. It is observed the decrease in torque difference $\left(\mathrm{d}_{\mathrm{L}}\right)$ by loading $\mathrm{Na}-\mathrm{Mt}$ which is an indicative of decrease in crosslinking density due to its agglomerated structure, on contrary torque difference tends to increase

Table 3. Rheological properties

\begin{tabular}{|l|c|c|c|c|}
\hline \multicolumn{1}{|c|}{ Filler (phr) } & $\begin{array}{c}\mathrm{d}_{\mathrm{L}} \\
\mathrm{dNm}\end{array}$ & $\begin{array}{c}\mathrm{tS} 2 \\
\mathrm{~min}\end{array}$ & $\begin{array}{c}\mathrm{tC90} \\
\mathrm{min}\end{array}$ & $\mathrm{MV}$ \\
\hline 0 & 17 & 2.5 & 5.14 & 28 \\
\hline Na-Mt-1 & 15 & 2.5 & 5.17 & 26 \\
\hline Na-Mt-2 & 14 & 2.7 & 5.20 & 24 \\
\hline Na-Mt-3 & 13 & 2.7 & 5.22 & 21 \\
\hline Na-Mt-4 & 11 & 2.8 & 5.30 & 20 \\
\hline Na-Mt-5 & 10 & 2.9 & 5.37 & 18 \\
\hline OMt -1 & 18 & 2.3 & 5.00 & 32 \\
\hline OMt -2 & 19 & 2.2 & 4.92 & 33 \\
\hline OMt -3 & 20 & 2.1 & 4.87 & 35 \\
\hline OMt -4 & 21 & 2.0 & 4.82 & 37 \\
\hline OMt -5 & 22 & 1.9 & 4.79 & 39 \\
\hline APT-OMt -1 & 19 & 2.2 & 4.90 & 33 \\
\hline APT-OMt -2 & 20 & 2.1 & 4.88 & 36 \\
\hline APT-OMt -3 & 21 & 2.0 & 4.86 & 38 \\
\hline APT-OMt -4 & 22 & 1.9 & 4.80 & 40 \\
\hline APT-OMt -5 & 23 & 1.8 & 4.72 & 42 \\
\hline
\end{tabular}

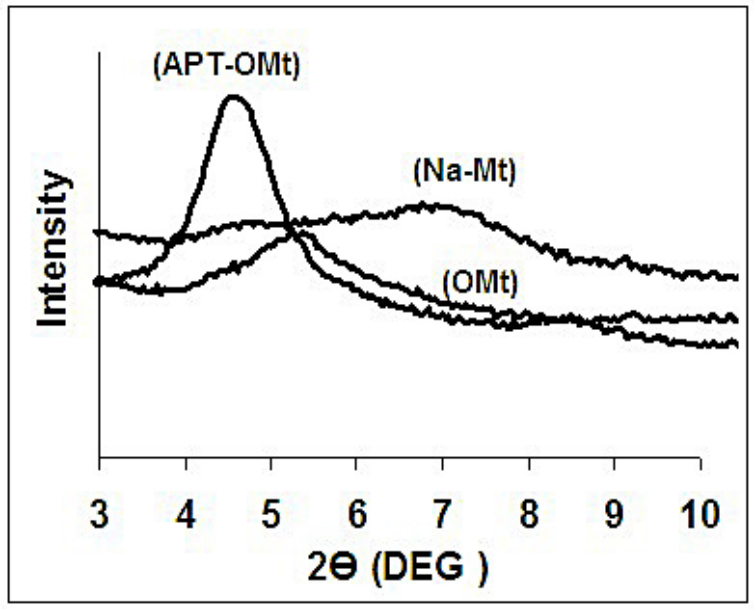

Fig. 4. XRD pattern of organomodified and unmodified montmorillonite

by loading organomodified montmorillonite due to its larger surface area which introduces more interaction sites for crosslinking. Results indicate deactivation in cure process by loading unmodi-
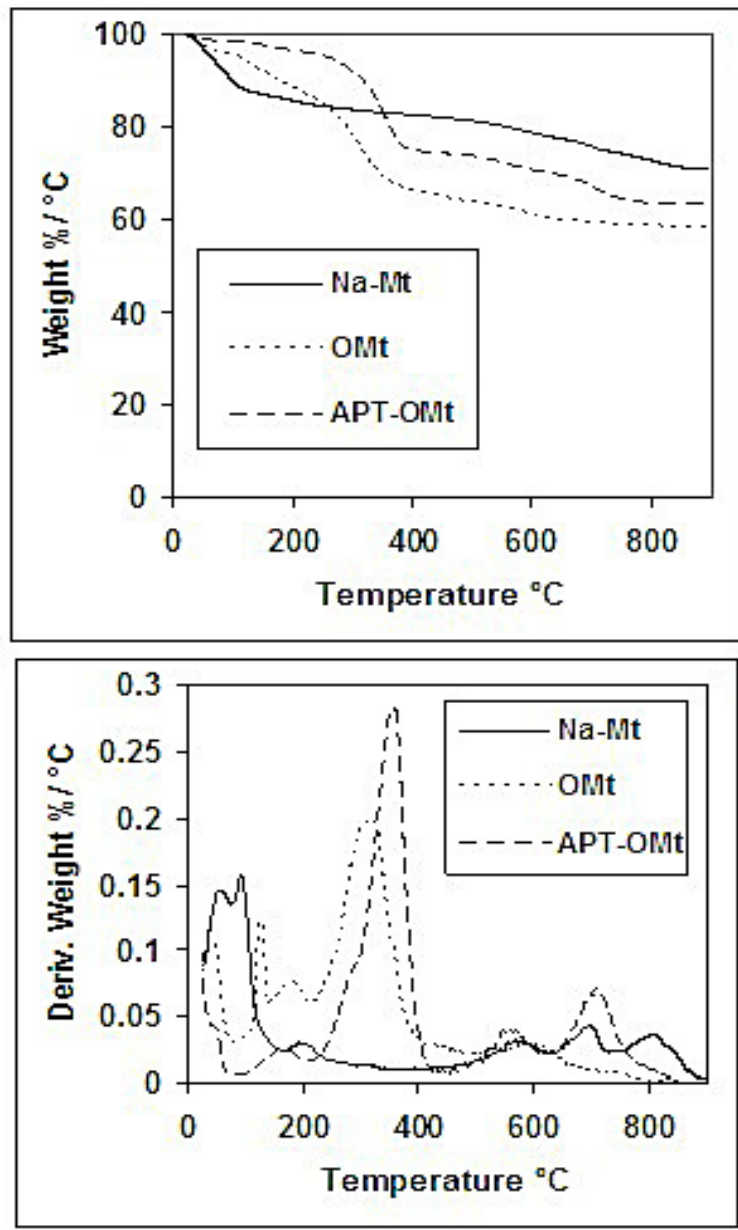

Fig. 5. Thermogravimetric analysis of: a) Mt, b) O-Mt, c) APT- OMt 
Table 4. Mechanical properties

\begin{tabular}{|c|c|c|c|c|c|c|c|c|}
\hline Filler (phr) & $\begin{array}{c}{\left[\mathrm{T}_{\mathrm{s}}\right]} \\
{[\mathrm{MPa}]}\end{array}$ & $\begin{array}{c}{\left[\mathrm{I}_{\mathrm{S}}\right]} \\
\mathrm{KJ} / \mathrm{m}\end{array}$ & $\begin{array}{c}200 \%[\mathrm{M}] \\
\mathrm{MPa}\end{array}$ & {$\left[E_{b}\right] \%$} & $\begin{array}{c}{[\mathrm{H}]} \\
\text { Shore A }\end{array}$ & $\begin{array}{c}{[\mathrm{ARI}]} \\
\%\end{array}$ & $\begin{array}{c}{\left[F_{f}\right]} \\
\text { Cycles } \\
\end{array}$ & $\begin{array}{c}{\left[\mathrm{C}_{\mathrm{s}}\right]} \\
\%\end{array}$ \\
\hline 0 & 8.82 & 10 & 0.88 & 1427 & 43.0 & 7.032 & 1423 & 45 \\
\hline Na-Mt-1 & 8.60 & 9.3 & 0.93 & 1424 & 43.6 & 6.985 & 1362 & 51 \\
\hline Na-Mt-2 & 8.20 & 8.6 & 0.98 & 1420 & 44.0 & 4.321 & 1234 & 56 \\
\hline Na-Mt-3 & 8.00 & 8.1 & 1.03 & 1418 & 44.7 & 3.221 & 1190 & 62 \\
\hline Na-Mt-4 & 7.90 & 7.4 & 1.09 & 1415 & 45.3 & 3.109 & 980 & 69 \\
\hline Na-Mt-5 & 7.80 & 6.8 & 1.15 & 1410 & 46.0 & 2.986 & 965 & 72 \\
\hline OMt -1 & 9.80 & 11.5 & 0.98 & 1420 & 44.2 & 9.886 & 1854 & 26 \\
\hline OMt -2 & 10.30 & 12.2 & 1.04 & 1415 & 45.0 & 12.551 & 1943 & 21 \\
\hline OMt -3 & 10.68 & 14.4 & 1.1 & 1406 & 46.0 & 13.076 & 2650 & 19 \\
\hline OMt -4 & 10.98 & 15.3 & 1.15 & 1400 & 47.0 & 16.031 & 3112 & 17 \\
\hline OMt -5 & 11.40 & 16.1 & 1.19 & 1390 & 47.6 & 18.223 & 3660 & 15 \\
\hline APT-OMt -1 & 10.29 & 13.2 & 1.07 & 1413 & 45.0 & 14.765 & 2150 & 21 \\
\hline APT-OMt -2 & 10.88 & 14.3 & 1.1 & 1405 & 45.9 & 17.876 & 2430 & 19 \\
\hline APT-OMt -3 & 11.27 & 16.1 & 1.17 & 1395 & 46.8 & 19.065 & 2650 & 17 \\
\hline APT-OMt -4 & 11.47 & 17.2 & 1.21 & 1390 & 48.0 & 20.543 & 3125 & 14 \\
\hline APT-OMt -5 & 11.86 & 19.3 & 1.26 & 1385 & 49.0 & 21.675 & 3670 & 12 \\
\hline
\end{tabular}

fied montmorillomite due to adsorption of curatives by silica surface of montmorillonite, making it unavailable for cure reaction. However by loading organic modified montmorillonite both optimum cure time and scorch time tend to decrease from OMt to APT-OMt which indicates that organic moieties serve in increasing the introduction and acceleration of crosslinks. It is observed that the mooney viscosity (MV) decreases by loading Na-Mt, this is may be attributed to poor interaction between the two incompatible phases, resulting in interlayer slip between phases, which tends to decrease by loading organomodified montmorillonite results in more homogeneous composites and higher mooney viscosity.

\section{Mechanical properties}

The effect of loading organomodified and unmodified Na-Mt on mechanical properties of CPN (Table 4) reveals a weak rubber - Na-Mt interaction results in lowering tensile strength, impact strength and resistance to flex fatigue, abrasion and compression set since, there is high amount of agglomerates of Na-Mt; these agglomerates played the role of an obstacle to molecular chain movement of the NR/ NBR, thereby initiating failure under stress. The improvement of mechanical properties of organomodified montmorillonite filled NR/NBR is related to the achievement of mesoporous surface more suitable for mechanical adhesion. The degree of reinforcement is related
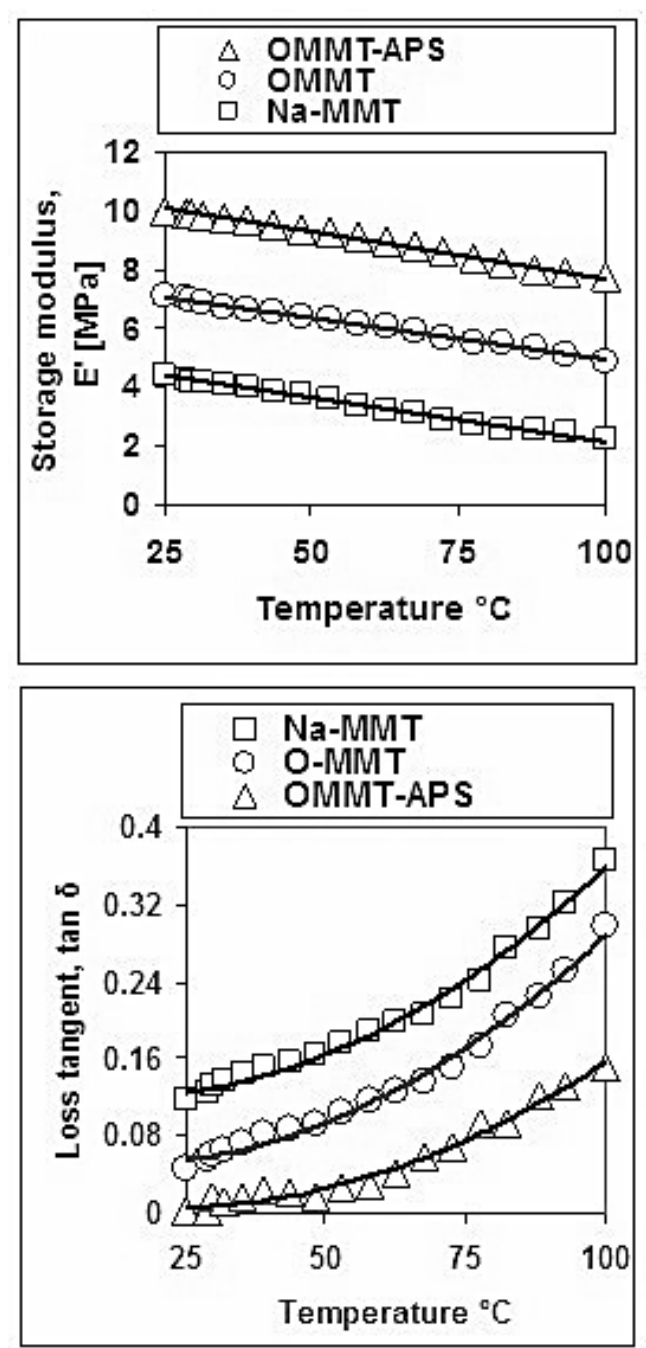

Fig. 6. Storage modulus; loss tangent for NR/NBR filled with 5 phr: Na-Mt; OMt; APT-OMt 

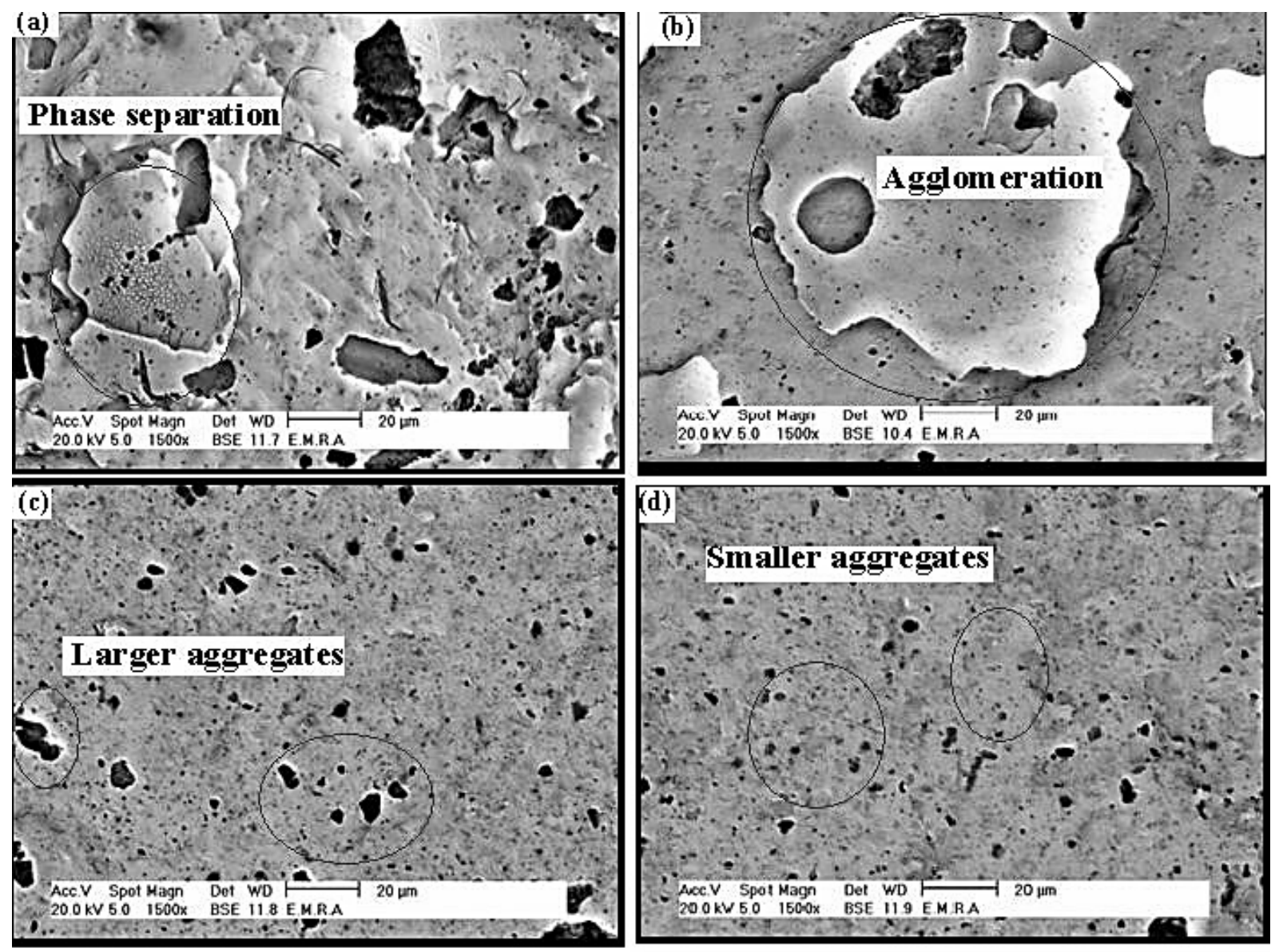

Fig. 7. SEM micrographs of NR/NBR filled with: a) 0 phr Na-Mt, b) 5 phr Na-Mt, c) $5 \mathrm{phr}$ OMt, d) $5 \mathrm{phr}$ APT-OMt

to textural properties, the increased surface area at the phase boundaries through organomodification play an influential role in causing compatibilization at a molecular level and the enhancement is larger for APT-OMt filled composites. Hardness and modulus tend to increase by loading of pristine and organomodified montmorillonite due to increased stiffness of rubber nanocomposites. On contrary elongation at break tends to decrease due to the adherence of the filler particles to rubber matrix causing stiffening effects on the polymer chain and decreasing stretching which follows the order $\mathrm{Na}-\mathrm{Mt}<\mathrm{OMt}<$ APT-OMt.

\section{Dynamic mechanical thermal properties (DMTA)}

Dynamic mechanical thermal properties of NR /NBR as shown in figure 6 indicate that organophilization of montmorillonite improves the interfacial adhesion by physical and chemical adsorption of rubber matrices on montmorillonite surface and thereby facilitating the stress transfer between the components which leads to a marked increase in storage modulus and lesser damping characteristics due to reduced chain mobility [14]. By increasing temperature molecular movement at the interface of composites which contributes to the value of the damping property $(\tan \delta)$, tends to increases, also molecular relaxation at high temperature loosens the molecular bonds, so E' value tends to decrease by increasing temperature.

\section{Morphology}

The morphology of the composites is quite important because it determines the general performance of the resulting composites. SEM micrographs of fracture surface of NR/NBR filled with Na-Mt and organically modified montmorillonite are shown in Figure 7. The results reveal that domains of (NBR) are separated from the continuous phase (NR). By addition of Na-Mt it will agglomerates and further weakens the polymer matrix. However by surface modification of 

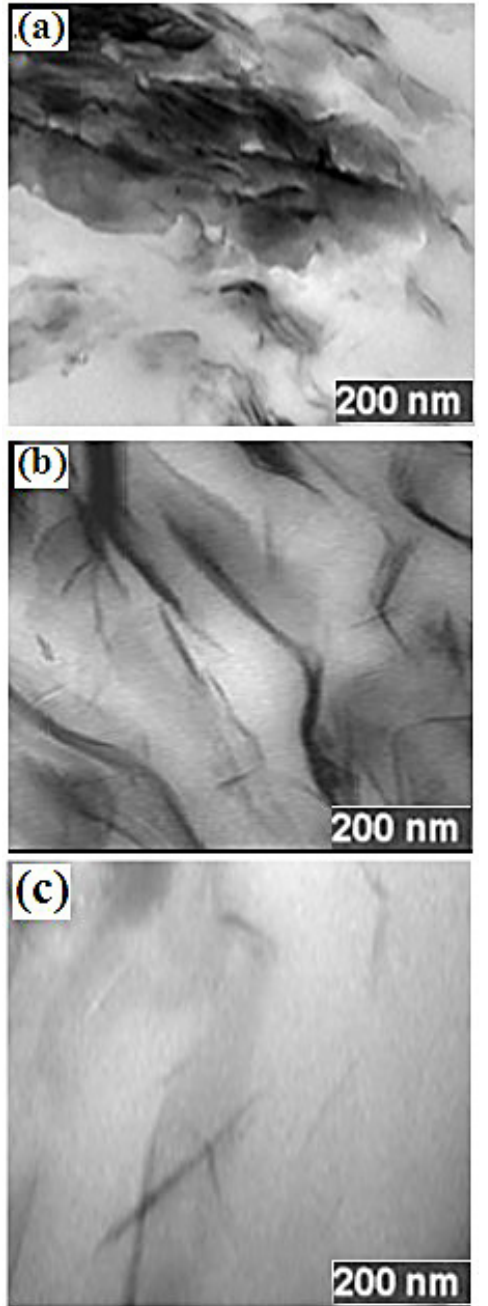

Fig. 8. TEM micrographs of NR/NBR filled with: a) $5 \mathrm{phr} \mathrm{Na}-\mathrm{Mt}$, b) $5 \mathrm{phr} \mathrm{OMt}$, c) $5 \mathrm{phr}$ APT-OMt

Na-Mt it will enhance the homogeneity of the two rubber phases.

In order to get more insight into the montmorillonite dispersion and the mechanism involved in compatibility by organophilization, the TEM images were taken for NR/NBR nanocomposite films containing $5 \%$ of unmodified and organomodified montmorillonite. As shown in Figure 8 clay mineral lamellae (darker) appear distributed in the rubber matrix (clearer) in different degrees of exfoliation. The presence of large agglomerates is observed for Na-Mt filled composite, however by organophilization of montmorillonite a well dispersed distribution of nanoclay is observed. organophilization reveals clay platelets, partially exfoliated lamellae and tactoids constituted of packets of non-exfoliated clay platelets. The bulks of organomodified montmorillonite dispersion are in the intercalated state, which affirms the better dispersion of organomodified
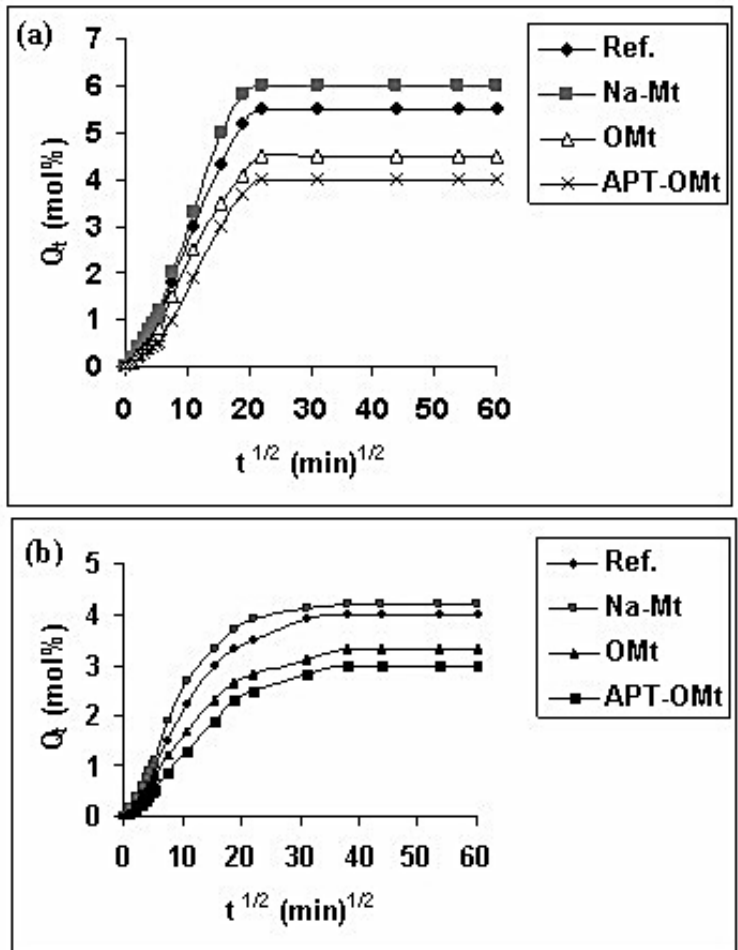

Fig. 9. Mole percent uptake of (NR/NBR) nanocomposites in benzene (a); butyl acetate (b) at $25^{\circ} \mathrm{C}$

montmorillonite in rubber matrix. APT-OMt shows higher degree of exfoliation than OMt and fewer are stacked proving the partial exfoliation and formation of agglomerates at few spots in the rubber matrix.

\section{Analysis of Adsorption data}

The diffusion curves of conventional crosslinked NR/NBR blends nanocomposites, using 0 phr Na-Mt (Ref.), 5 phr Na-Mt, 5 phr O-Mt and $5 \mathrm{phr}$ APT- OMt in benzene and butyl acetate are shown in Figure 9 and obtained by plotting $Q_{t}$ (mole\% uptake per $100 \mathrm{~g}$ of the solvent) against square root time $\left(\mathrm{t}^{1 / 2}\right)$ in minutes. Adsorption curves are similar in nature initial portions are slightly sigmoidal in shape but later level off.

\section{Effect of organophilization of montmorillonite}

The diffusion of the penetrant solvent depends on the concentration of free space available in the matrix to accommodate the penetrant molecule. The addition of Na-Mt increases the availability of free spaces this can be a result of presence of agglomerates due to hydrophilic nature of Na-Mt and solvent uptake is found to get increased compared to unfilled rubber blend 


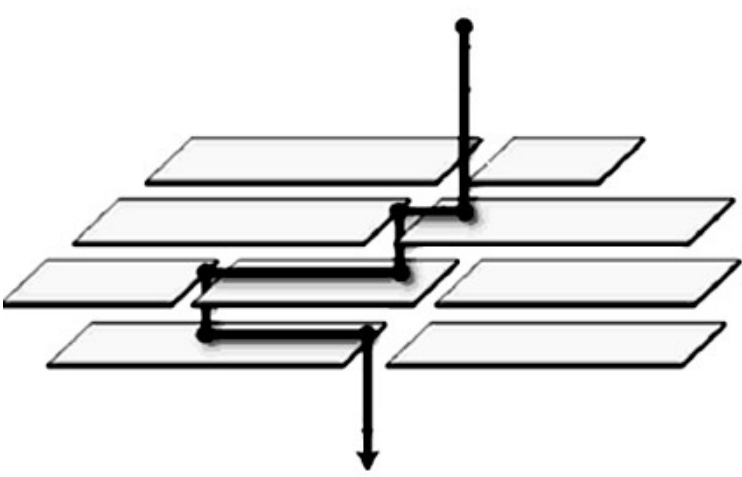

Fig. 10. Tortuous path created by organomodified montmorillonite platelets

composite (Ref.). However the intercalated/exfoliated morphology of organomodified CPN hinders the movement of penetrant molecules. The local mobility of polymers segments gets restricted by organic moieties and improves the solvent resistance due to the formation of tortuous path as shown in figure 10 which reduces the diffusion of penetrating molecules in rubber matrices.

\section{Effect of penetrant size}

Among the solvents used in this work, benzene (Mwt 78.11) shows the maximum value of Q, mol \% and butyl acetate (116.16) the minimum. The decrease in $\mathrm{Q}$, mol \% uptake with increase in penetrant size might be due to the greater activation energy needed for activation of the diffusion process [15].

\section{Diffusivity, adsorpitivity and permeability}

Diffusivity is a kinetic parameter which depends on the polymer segmental mobility [16]. It is determined using the relation:

$$
\mathrm{D}=\pi(\mathrm{h} \theta / 4 Q \theta)^{2}
$$

where: $\mathrm{D}$ the diffusion coefficient; $\theta$ is the slope of adsorption curves before attainment of
$50 \%$ equilibrium, $h$ is the initial thickness of the polymer sample and $\mathrm{Q}_{\infty}$ has the same meaning as in equation (3).

Corrections to $\mathrm{D}$ values are essential, this has been done by calculating the intrinsic diffusion coefficient $\mathrm{D}^{*}$ from the volume fraction $\left(\mathrm{V}_{\mathrm{r}}\right)$ of the solvent-swollen rubber, using the relation:

$$
\mathrm{D}^{*}=\mathrm{D} /\left(\mathrm{V}_{\mathrm{r}}\right)^{7 / 3}
$$

Adsorption coefficient is a thermodynamic parameter which depends on the strength of the interactions in the polymer-solvent mixture.

$$
\mathrm{S}=\mathrm{M}_{\infty} / \mathrm{M}_{o}
$$

where: $M_{\infty}$ is the mass of solvent taken up at equilibrium and $M_{\circ}$ is the initial mass of polymer sample.

Permeation is a collective process of diffusion and adsorption and hence the permeability of solvent molecules into polymer membrane depends upon both diffusivity and adsorptivity so the permeation coefficient can be described as follow:

$$
\mathrm{P}=\mathrm{D} . \mathrm{S}
$$

For different NR/NBR blends with $5 \mathrm{phr}$ filler loading it is shown that intrinsic diffusion coefficient, adsorption coefficient and permeation values (Table 5) are higher for Na-Mt filled nanocomposite due to the development of microcracks on the surface and in the bulk of the material leading to peeling and surface dissolution of nanocomposites. However the lower values of organomodified CPN have been attributed to the lower void content and higher clay mineral /matrix adhesion and the reinforcement is higher for APT-OMt filled nanocomposite due to dual enhancement by CTAB and APS. The same trend is observed in both aliphatic and aromatic hydrocarbons but the magnitude is different, due to the difference in penetrants size.

Table 5. Values of diffusion coefficient, adsorption coefficient and permeation coefficient

\begin{tabular}{|l|c|c|c|c|c|c|}
\hline \multirow{2}{*}{ Filler (phr) } & \multicolumn{2}{|c|}{$\mathrm{D}^{*} \times 10^{6} \mathrm{~cm}^{2} \cdot \mathrm{sec}^{-1}$} & \multicolumn{2}{c|}{$\mathrm{Sg} \mathrm{g}^{-1}$} & \multicolumn{2}{c|}{$\mathrm{P}(\mathrm{DS}) \times 10^{7} \mathrm{~cm}^{2} \cdot \mathrm{sec}^{-1}$} \\
\cline { 2 - 7 } & $\mathrm{B}$ & $\mathrm{BA}$ & $\mathrm{B}$ & $\mathrm{BA}$ & $\mathrm{B}$ & $\mathrm{BA}$ \\
\hline Ref. & 8.5 & 7.0 & 4.68 & 4.5 & 3.978 & 3.150 \\
\hline Na-Mt-5 & 9.0 & 7.8 & 5.00 & 4.8 & 4.500 & 3.744 \\
\hline OMt-5 & 7.0 & 5.6 & 3.90 & 3.5 & 2.730 & 1.960 \\
\hline APT-OMt-5 & 6.0 & 4.8 & 3.12 & 3.0 & 1.872 & 1.440 \\
\hline
\end{tabular}




\section{CONCLUSIONS}

Organophilic modification of montmorillonite was done using CTAB followed by silylation using APT. Organomodified montmorillonite was successfully used as a compatiblizer for dissimilar NR /NBR rubber blends. The morphology of the blends became homogeneous with the presence of intercalated/exfoliated organically modified montmorillonite. Rheological and mechanical properties of organomodified CPN showed that organic moieties served in increasing the introduction and acceleration of crosslinks leading to improvement of mechanical properties. Dynamic mechanical thermal analysis (DMTA) revealed a marked increase storage modulus ( $\left.E^{\prime}\right)$ and lesser damping characteristics by loading organomodified montmorillonite, this corresponds to the higher reinforcing efficiency of organomodified montmorillonite in rubber matrix. Organomodified CPN showed enhanced barrier properties assisted by the formation of tortuous path which retarded solvent transport through rubber matrices.

\section{REFERENCES}

1. Duryodhan M. Elastomer blends. Rubber Chemistry and Technology, 75(3), 2002, 365-427.

2. Singh R. and Sangwan S. Natural rubber/butadiene rubber/ethylene- propylene-diene-monomer blends by various approaches and therefore improves the final mechanical properties. International Journal of Latest Trends in Engineering and Technology, 5(1), 2015, 289-291.

3. Lamlong C., Taweepreda W., Nu-Mard, R. and Songsiriritthigul R. Investigation of sulfur crosslinking interfacial of natural rubber (NR) blending with carboxyalted styrene butadiene rubber (XSBR) using x-ray absorption spectroscopy. Advanced Material Research, 1087(5), 2015, 131-136.

4. Miller-Chou B.A. and Koenig J.L. A review of polymer dissolution. Progress in Polymer Science, 28(8), 2003, 1223-1270.

5. Kroshefsky R.D., Jack L.P. and Duryodhan M. Role of compatibilization in polymer nanocomposites. Rubber Chemistry and Technology, 82(3),
2009, 340-368.

6. Essawy H. and El-Nashar D. The use of montmorillonite as reinforcing and compatibilizing filler for NBR/SBR rubber blend. Polymer Testing, 23(7), 2004, 803-807.

7. Hrachova J., Chodak B. and Komadel P. Modification and characterization of montmorillonite fillers used in composites with vulcanized natural rubber. Chemical Papers, 63(1), 2009, 55-61.

8. Chiou J.Y., Hsu R.S., Chiu C.W. and Lin S.J. A stepwise mechanism for intercalating hydrophobic organics into multilayered clay nanostructures. RSC Advances, 3(31), 2013, 12847-12854.

9. Mrah L., Meghabar R. and Belbachir M. The Characteristics of poly propylene oxide/montmorillonite nanocomposites. Journal of Nanomedicine and Nanotechnology, 6(1), 2015, 1-7.

10. Piscitelli F., Posocco P., Toth R., Fermeglia M., Pricl S., Mensitieri G. and Lavorgna M. Sodium montmorillonite silylation: Unexpected effect of the aminosilane chain length. Journal of Colloid and Interface Science, 351(1), 2010, 108-115.

11. Lippens B.C. and De Boer J.H. Studies on pore systems in catalysts $\mathrm{V}$. The $t$ method. Journal of Catalysis, 4(3), 1965, 319-323.

12. Quercia G., Lazaro A., Geus J.W. and Brouwers H.J.H. Characterization of morphology and texture of several amorphous nano-silica particles used in concrete. Cement and Concrete Composites, 44(9), 2013, 77-92.

13. Barret E.P., Joyner L.G. and Halenda P.P. The determination of pore volume and area distributions in porous substances. I. Computations from nitrogen isotherms. Journal of American Chemical Society, 73(1), 1951, 373-80.

14. Fu D. H., Zhan Y. H., Yan N. and Xia H. S. Comparative investigation on strain induced crystallization for graphene and carbon nanotubes filled natural rubber composites. Express Polymer Letters, 9(7), 2015, 597-607.

15. Dasan K., Unnikrishnan G. and Purushothaman E. Solvent transport through carbon black filled poly (ethylene-co-vinyl acetate) composites. Express Polymer Letters, 2(5), 2008, 382-390.

16. Saritha A., Joseph K., Boudenne A. and Thomas S. Mechanical, thermophysical, and diffusion properties of $\mathrm{TiO}_{2}$-filled chlorobutyl rubber composites. Polymer Composites, 32(10), 2011, 1681-1687. 